\title{
Intermediate input linkage and carbon leakage
}

\section{CCEP Working Paper 1606 \\ Sep 2016}

\section{Zengkai Zhang}

College of Management and Economics, Tianjin University

\section{ZhongXiang Zhang}

College of Management and Economics, Tianjin University

\begin{abstract}
Climate regulations tend to target energy intensive sectors whose products are widely used in industrial production as intermediate inputs, such as electricity, and the carbon abatement may be partially offset by intermediate input-led leakage. This paper aims to examine the impact of intermediate input linkage on the carbon leakage both theoretically and empirically. We develop a Harberger-type model with an input-output linkage structure, identify four leakage effects and derive closed-form solutions for these leakage effects. For empirical simulation, we build a computable general equilibrium model of China's economy and introduce Structural Decomposition Analysis to link both the theoretical and empirical models. When imposing a carbon price on the electricity generation sector, our results show significant carbon leakage. Our decomposition analysis further suggests that such leakage is mainly through the production substitution effect, followed by the multiplier effect. Both of the two effects are closely related to the intermediate input linkage, and thus shed some light on the importance of considering sectoral linkage when discussing the carbon leakage issue of climate policies.
\end{abstract}




\section{Keywords:}

Carbon leakage; sectoral linkage; climate regulation; general equilibrium model; production substitution effect; multiplier effect

\section{JEL Classification:}

Q55; Q58; Q43; Q48; O13; O31; O33; O44; F18

\section{Suggested Citation:}

Zhang, Z. and Zhang, ZX. (2016), Intermediate input linkage and carbon leakage, CCEP Working Paper 1606, Sep 2016. Crawford School of Public Policy, The Australian National University.

\section{Address for Correspondence:}

ZhongXiang Zhang

Distinguished University Professor

College of Management and Economics

Tianjin University

92 Weijin Road

Tianjin 300072

China

Tel: +86 2287370560

Email: ZhangZX@tju@edu.cn

The Crawford School of Public Policy is the Australian National University's public policy school, serving and influencing Australia, Asia and the Pacific through advanced policy research, graduate and executive education, and policy impact.

The Centre for Climate Economics \& Policy is an organized research unit at the Crawford School of Public Policy, The Australian National University. The working paper series is intended to facilitate academic and policy discussion, and the views expressed in working papers are those of the authors. Contact for the Centre: Dr Frank Jotzo, frank.jotzo@anu.edu.au 


\title{
Intermediate input linkage and carbon leakage
}

\author{
Zengkai Zhang; ZhongXiang Zhang* \\ College of Management and Economics, Tianjin University, Tianjin 300072, China
}

\begin{abstract}
:
Climate regulations tend to target energy intensive sectors whose products are widely used in industrial production as intermediate inputs, such as electricity, and the carbon abatement may be partially offset by intermediate input-led leakage. This paper aims to examine the impact of intermediate input linkage on the carbon leakage both theoretically and empirically. We develop a Harberger-type model with an input-output linkage structure, identify four leakage effects and derive closed-form solutions for these leakage effects. For empirical simulation, we build a computable general equilibrium model of China's economy and introduce Structural Decomposition Analysis to link both the theoretical and empirical models. When imposing a carbon price on the electricity generation sector, our results show significant carbon leakage. Our decomposition analysis further suggests that such leakage is mainly through the production substitution effect, followed by the multiplier effect. Both of the two effects are closely related to the intermediate input linkage, and thus shed some light on the importance of considering sectoral linkage when discussing the carbon leakage issue of climate policies.
\end{abstract}

JEL classifications: Q55; Q58; Q43; Q48; O13; O31; O33; O44; F18

Keywords: Carbon leakage; Sectoral linkage; Climate regulation; General equilibrium model; Production substitution effect; Multiplier effect

\section{Introduction}

Corresponding author: ZhongXiang Zhang, Distinguished University Professor, College of Management and Economics, Tianjin University, 92 Weijin Road, Tianjin 300072, China.

E-mail address: ZhangZX@tju.edu.cn. 
With two-week-long hard work and concerted efforts of all the parties involved in December 2015, a landmark Paris Agreement was reached, charting a clear course for global cooperation on fighting climate change to hold the average rise in global temperature well below $2^{\circ} \mathrm{C}$ above pre-industrial levels and to pursue efforts to limit the temperature increase to $1.5^{\circ}$ (UNFCCC, 2015). For governments around the world, the urgent task of implementing the details of the agreement is to prepare plans and actions in line with their national priorities to achieve the goals set in their intended nationally determined contributions. Because energy-intensive sectors are major carbon emitters, it should come as no surprise that climate policies will target at these sectors. This would lead to carbon leakage across sectors, given that the products of the regulated sectors are widely used in industrial production as intermediate inputs, such as electricity and the share of intermediate inputs per unit of outputs increases gradually (Xu and Dietzenbacher, 2014). This domestic leakage may in turn offset the carbon reduction of the regulated sectors (Zhang, 2012; Baylis et al., 2014; World Bank, 2015). This highlights that intermediate input linkage may be an important influence factor of carbon leakage. For instance, Böhringer et al. (2014) found that domestic industries may rather suffer than benefit from anti-leakage measures under the consideration of intermediate input structure. The purpose of this study is to clarify the relation between the intermediate input linkage and the carbon leakage, and to evaluate the leakage effects of China's climate regulations on the electricity generation sector.

The theoretical model of this study builds on Harberger (1962)-type general equilibrium model aimed to study the effects of climate policies (e.g., Fullerton and 
Heutel, 2007; Fullerton and Monti., 2013; Lanzi and Wing, 2013; Baylis et al., 2014; Elliott and Fullerton, 2014; Rausch and Giacomo, 2016). However, these studies mainly adopt the independent sector assumption or vertical serctoral linkage (e.g., Bushnell and Mansur, 2011; Fullerton et al., 2012; Sen, 2015), and a systematic study on the effect of sectoral linkage on carbon leakage is lacking. To capture the impact of sectoral linkage on the carbon leakage, we extend Baylis et al.'s two-independent-sector model (Baylis et al., 2014) by introducing intermediate input linkage structure. This study disentangles four leakage effects ${ }^{1}$ and derives the closed-form solutions for these effects. All of these effects are related to the intermediate input linkage either directly or indirectly.

We find that the intermediate input linkage has important implications for assessing the carbon leakage problem. First, the change of gross output and emissions due to consumption change is influenced by the intermediate input linkage structure directly, which is named the multiplier effect. Second, the producers would adjust the intermediate input structure because climate policies result in higher price level of the energy intensive products, which is closely related to the production substitution effect. Third, the intermediate input linkage has an indirect impact on the magnitude of the scale and consumption substitution effects. For instance, close industrial linkage means that the relative price change is small, and the consumption

1 The literature presents different leakage channels, such as fossil fuel channel (e.g. Dröge et al., 2009), competitiveness channel (e.g. Bruvoll and Fæhn, 2006; Zhang, 2012), terms-of-trade effect (e.g. Baylis et al., 2014; Di Maria and Van der Werf, 2008), technology channel (e.g. Golombek and Hoel, 2004; Sijim et al., 2004; Gerlagh and Kuik, 2014; Dröge et al., 2009), abatement resource effect (Baylis et al., 2014), intertemporal channel (e.g. Eichner and Pethig, 2015; Michielsen, 2014), and scale channel (e.g. Kuik and Gerlagh, 2003; Karp, 2013). The Harberger-type model is applicable for discussing the short term effects of climate policies; therefore, this study does not consider the technology development and intertemporal channel of carbon leakage. In addition, similar to Baylis et al.'s study (2014), this study omits the fossil fuel channel. 
substitution effect, which reflects the environmental impact of consumption structure adjustment due to relative price change, would be relatively small.

The empirical study of this paper focuses on the effect of climate regulations on the electricity generation sector in China using a computable general equilibrium (CGE) model. The electricity not only takes the largest share of direct emissions but also is a crucial intermediate input used in most production activities. China's carbon emissions trading pilots pay special attention to the impact of intermediate input linkage on the environmental effect of climate regulations. One key feature of China's carbon trading pilots is the regulation on both direct and indirect emissions from electricity generation (Zhang, 2015a,b). The previous studies (e.g., Bernstein et al., 1999; Babiker, 2001; Kuik and Gerlagh, 2003; Mathiesen and Mæstad, 2004; Barker et al., 2007; Antimiani et al., 2013; Meunier et al., 2014; Böhringer et al., 2016) focus mainly on the developed regions' regulations and on leakages between developed and developing countries. Our study focuses on an analysis on the carbon leakage of China's climate regulations between regulated sector and unregulated sectors, and thus will broaden our understanding of carbon leakage and enrich the policy relevance of existing studies.

There is a close relationship between the Harberger-type model and the computable general equilibrium (CGE) model, which are adopted for theoretical and numerical studies of the paper, respectively. Chumacero and Schmidt-Hebbel (2004) classify Harberger-type model as a CGE model. Kortum (2011) states that the Harberger-type model can be observed as a simpler version of the CGE model. The previous literature links these two models by changing the key parameters of the CGE model (Carbone, 2013) or by inserting parameters taken from a CGE model to the theoretical results (Lanzi and Wing, 2013). Adopting Structural Decomposition 
Analysis, this study proposes another method to link the theoretical and numerical models, and we quantitatively evaluate the magnitude of four leakage effects. The simulation results show that China's climate regulations on the electricity generation sector would generate a negative sectoral leakage, which is mainly determined by the production substitution effect and the multiplier effect, both of which have a close relation with the sectoral linkage.

This study contributes to the literature in several ways. First, this study clarifies the direct and indirect impact of intermediate input linkage on carbon leakage of sectoral climate regulations from the perspectives of four different leakage effects. Second, the study develops a Harberger-type model with an input-output linkage structure, which can represent two countries linked through intermediate goods trade or a closed economy with two interdependent sectors. Third, the study proposes a method to link the theoretical and numerical models by adopting Structural Decomposition Analysis and quantitatively evaluates the magnitude of different leakage effects. The policy implication is that policy makers should consider the domestic sectoral linkage in the determination of climate regulations and anti-leakage measures.

The remainder of the paper is organized as follows. Section 2 develops a Harberger-type theoretical model with an input-output linkage structure and derives closed-form expressions of four different leakage effects. Section 3 builds China's computable general equilibrium model for empirical simulation and introduces Structural Decomposition Analysis to link the theoretical and empirical models. Section 4 discusses the simulation results. The conclusions are presented in Section 5.

\section{The theoretical model}


With the development of production fragmentation, firms in different sectors and regions are more closely connected to each other through intermediate input linkage. Sectoral linkage may have an obvious impact on the environmental effect of climate regulations. In order to present the relation between intermediate input linkage and carbon leakage, this study extends the model presented in Baylis et al. (2014), which assumes two independent sectors by introducing the sectoral input-output linkage structure. Our model allows us to quantify the impact of intermediate input linkage on carbon leakage under a small change in carbon tax. The theoretical model of this study is presented in the following subsection.

\subsection{Theoretical model}

\subsubsection{Production}

In a closed economy, two competitive sectors $(i, j=X, Y)$ each use intermediate input $M_{i}$, clean input $K_{i}$ and carbon emissions $E_{i}(m, n=M, K, E)$, with decreasing marginal products in a constant return to scale production function. The final output of the sector $i\left(O_{i}=f\left(M_{i}, K_{i}, E_{i}\right)\right)$ satisfies both final demand of consumers $\left(C_{i}\right)$ and intermediate demand of the other sector $j\left(M_{j}\right)$. The intermediate input share is $\xi_{x M}=M_{x} P_{y} / O_{x} P_{x}$ and $\xi_{y M}=M_{y} P_{x} / O_{y} P_{y}$. The clean and dirty factor input share is $\xi_{x K}=\left(1-\xi_{x M}\right) \theta_{x k}, \quad \xi_{x E}=\left(1-\xi_{x M}\right) \theta_{x e}, \quad \xi_{y K}=\left(1-\xi_{y M}\right) \theta_{y k}, \quad \xi_{y E}=\left(1-\xi_{y M}\right) \theta_{y e}$, where $\theta_{i k}$ and $\theta_{i e}\left(\theta_{i k}+\theta_{i e}=1\right)$ is the share of clean and dirty input to gross factor input. We assume that sector $X$ has greater carbon intensity $\left(\xi_{x E}>\xi_{y E}\right)$. Differentiating each sector's production function, we have:

$$
\hat{O}_{i}=\xi_{i M} \hat{M}_{i}+\xi_{i K} \hat{K}_{i}+\xi_{i E} \hat{E}_{i}
$$

The presence of a hat notation above any variable represents each proportional 
change (e.g., $\hat{O}_{i}=\Delta O_{i} / O_{i}$ ). Firms would adjust the input structure with the relative price change, and this corresponds to the production substitution effect. For instance, they would reduce carbon emissions per unit of output by incremental capital investment. Harberger-type model with three or more inputs usually adopts Allen elasticities of substitution. Karney (2016) proposes a method to switch from Allen to Morishima elasticities and demonstrates a one-to-one numerical equivalence of models using two different elasticities. Therefore, our paper also adopts Allen elasticities of substitution and defines the elasticity of substitution between intermediate and factor inputs of sector $i$ as $e_{m n}^{i}$, we obtain:

$$
\left\{\begin{array}{l}
\hat{M}_{i}-\hat{E}_{i}=\xi_{i M}\left(e_{M M}^{i}-e_{E M}^{i}\right) \hat{P}_{j}+\xi_{i K}\left(e_{M K}^{i}-e_{E K}^{i}\right) \hat{P}_{k}+\xi_{i E}\left(e_{M E}^{i}-e_{E E}^{i}\right) \hat{P}_{e i} \\
\hat{K}_{i}-\hat{E}_{i}=\xi_{i M}\left(e_{K M}^{i}-e_{E M}^{i}\right) \hat{P}_{j}+\xi_{i K}\left(e_{K K}^{i}-e_{E K}^{i}\right) \hat{P}_{k}+\xi_{i E}\left(e_{K E}^{i}-e_{E E}^{i}\right) \hat{P}_{e i}
\end{array}\right.
$$

The capital is moveable across sectors, with the same return $\left(P_{k x}=P_{k y}=P_{k}\right)$ and a fixed supply $\left(\bar{K}=K_{x}+K_{y}\right)$. By completely differentiating the capital constraint equation $\bar{K}=K_{x}+K_{y}$, we obtain:

$$
\alpha_{x} \hat{K}_{x}+\alpha_{y} \hat{K}_{y}=0
$$

where $\alpha_{x}$ and $\alpha_{y}$ are the sectoral share of capital distribution between two sectors and satisfy $\alpha_{x}+\alpha_{y}=1$

\subsubsection{Price}

Perfect competition and constant returns to scale imply zero profit, so $P_{i} O_{i}=P_{j} M_{i}+P_{k} K_{i}+P_{e i} E_{i}$. Completely differentiating these equations and using companies' profit maximizing first-order conditions yield:

$$
\hat{P}_{i}+\hat{O}_{i}=\xi_{i M}\left(\hat{P}_{j}+\hat{M}_{i}\right)+\xi_{i K}\left(\hat{P}_{k}+\hat{K}_{i}\right)+\xi_{i E}\left(\hat{P}_{e i}+\hat{E}_{i}\right)
$$


According to equation (1), we find the relationship of the proportional change in price levels.

$$
\hat{P}_{i}=\xi_{i M} \hat{P}_{j}+\xi_{i K} \hat{P}_{k}+\xi_{i E} \hat{P}_{e i}
$$

The price level faced by consumers $(\hat{I})$ is determined by the price level of two sectors $\left(\hat{I}=\frac{C_{x} \Delta P_{x}+C_{y} \Delta P_{y}}{C_{x} P_{x}+C_{y} P_{y}}=\frac{C_{x} P_{x}}{C_{x} P_{x}+C_{y} P_{y}} \Delta P_{x} / P_{x}+\frac{C_{y} P_{y}}{C_{x} P_{x}+C_{y} P_{y}} \Delta P_{y} / P_{y}\right)$. Supposing $\vartheta_{i}$ is the share of income spent on sector $i \quad\left(\vartheta_{x}=P_{x} C_{x} /\left(P_{x} C_{x}+P_{y} C_{y}\right)\right.$, $\vartheta_{y}=P_{y} C_{y} /\left(P_{x} C_{x}+P_{y} C_{y}\right)$, and $\left.\vartheta_{x}+\vartheta_{y}=1\right)$, we obtain:

$$
\hat{I}=\vartheta_{x} \hat{P}_{x}+\vartheta_{y} \hat{P}_{y}
$$

According to the production approach of nominal gross domestic product $(N)$, the mathematical expression is $N=\left(1-\xi_{x M}\right) O_{x} P_{x}+\left(1-\xi_{y M}\right) O_{y} P_{y}$. By log-linearizing the above equation, we obtain:

$$
\hat{N}=\frac{\vartheta_{x}+\xi_{y M} \vartheta_{y}}{1-\xi_{x M} \xi_{y M}}\left(1-\xi_{x M}\right)\left(\hat{O}_{x}+\hat{P}_{x}\right)+\frac{\xi_{x M} \vartheta_{x}+\vartheta_{y}}{1-\xi_{x M} \xi_{y M}}\left(1-\xi_{y M}\right)\left(\hat{O}_{y}+\hat{P}_{y}\right)
$$

The economic scale is represented by the real gross domestic product $(G)$, which satisfies $G=N / I$. Through $\log$-linearzing, we obtain $\hat{G}=\hat{N}-\hat{I}$. Climate regulations would shock the economy scale and influence the final emissions. The scale effect of carbon leakage is obtained from the change of real gross domestic product.

\subsubsection{Consumption}

We assume that all tax revenue $\left(R=P_{e x} E_{x}+P_{e y} E_{y}\right)$ is returned to individuals via a lump-sum rebate. Under the budget constraint $\left(r \bar{K}+R \geq P_{x} C_{x}+P_{y} C_{y}\right)$, identical individuals maximize homothetic utility $\left(U\left(C_{x}, C_{y} ; E_{\text {total }}\right)\right)$ by choosing products from 
the two sectors. This paper assumes that the welfare gain from carbon reduction $\left(\Delta E_{\text {total }}=\Delta E_{x}+\Delta E_{y}\right)$ is separable in utility (Baylis et al., 2013) and focuses on the welfare effects from consumption. Under the assumption that pollution is separable in utility, we define $\sigma_{u}$ as the elasticity of substitution in utility between different products.

$$
\hat{C}_{x}-\hat{C}_{y}=\sigma_{u}\left(\hat{P}_{y}-\hat{P}_{x}\right)
$$

Consumers would adjust the consumption structure with the final price change, which influences the sectoral emissions. We obtain the consumption substitution effect of carbon leakage. According to the product market clearance assumption ${ }^{2}$ and the intermediate input share, we obtain $O_{x} P_{x}=C_{x} P_{x}+\xi_{y M} O_{y} P_{y}$ and $O_{y} P_{y}=C_{y} P_{y}+\xi_{x M} O_{x} P_{x}$. Completely differentiating the above two equations yields:

$$
\begin{aligned}
& \hat{O}_{x}=\hat{C}_{x}+\frac{\left(\sigma_{u}-1\right) \xi_{y M} \vartheta_{y}}{\vartheta_{x}+\xi_{y M} \vartheta_{y}}\left(\hat{P}_{x}-\hat{P}_{y}\right) \\
& \hat{O}_{y}=\hat{C}_{y}+\frac{\left(\sigma_{u}-1\right) \xi_{x M} \vartheta_{x}}{\xi_{x M} \vartheta_{x}+\vartheta_{y}}\left(\hat{P}_{y}-\hat{P}_{x}\right)
\end{aligned}
$$

The final output change due to unit consumption change is influenced by the intermediate input coefficient $\xi_{i M}$, which is named the multiplier effect. In addition, equation (8) shows that the multiplier effect has a close relation with the consumption substitution elasticity. $\sigma_{u}=1$ means that the share of income spent on regulated and unregulated produces keeps consistent $\left(C_{x} P_{x}=C_{y} P_{y}\right)$. Then the final output has a linear relation with the final consumption, and two variables share the same percentage change.

2 The product market clearance implies that that the value of gross output equals the sum of intermediate input and final demands $O_{x}=C_{x}+M_{y}$ and $O_{y}=C_{y}+M_{x}$. 


\subsubsection{Climate policy}

We assume that a climate regulation only applies to the carbon intensive sector $X$.

$$
\begin{aligned}
& \hat{P}_{e x}=\tau \\
& \hat{P}_{e y}=0
\end{aligned}
$$

In addition, this paper assumes the capital price level is chosen as the numeraire. $\hat{P}_{k}=0$. There are 18 variables and 18 equations for the theoretical analytical framework, and the model is solvable mathematically. The parameters, variables and equations of the theoretical model are summarized in Appendix A.

\subsection{Decomposition analysis of theoretical results}

\subsubsection{Scale effect}

The environmental effects of climate policies through the expansion or contraction of the overall economic scale, which is represented by real gross domestic product (real GDP, $G$ ), is named the scale effect $(S E)$. The mathematical expression of the percentage change of $G$ is shown as below.

$$
\begin{aligned}
\hat{G} & =\frac{\left(\vartheta_{x}+\xi_{y M} \vartheta_{y}\right)\left(1-\xi_{x M}\right) \alpha_{y}-\left(\xi_{x M} \vartheta_{x}+\vartheta_{y}\right)\left(1-\xi_{y M}\right) \alpha_{x}}{1-\xi_{x M} \xi_{y M}}\left(\sigma_{u}+\frac{\left(1-\sigma_{u}\right) \xi_{y M} \vartheta_{y}}{\vartheta_{x}+\xi_{y M} \vartheta_{y}}+\frac{\left(1-\sigma_{u}\right) \xi_{x M} \vartheta_{x}}{\xi_{x M} \vartheta_{x}+\vartheta_{y}}\right) \frac{\left(1-\xi_{x M}\right)\left(\xi_{y M}-1\right)}{1-\xi_{x M} \xi_{y M}} \theta_{x e} \tau \\
& +\frac{\left(\vartheta_{x}+\xi_{y M} \vartheta_{y}\right)\left(1-\xi_{x M}\right)+\left(\xi_{x M} \vartheta_{x}+\vartheta_{y}\right)\left(1-\xi_{y M}\right)}{1-\xi_{x M} \xi_{y M}}\left(1-\xi_{x M}\right)\left[\xi_{x M} \alpha_{x}\left(e_{M E}^{x}-e_{K E}^{x}\right)-\left(1-\xi_{x M}\right) \alpha_{x}\left(e_{K E}^{x}-e_{E E}^{x}\right) \vartheta_{x e}\right. \\
& \left.+\frac{\xi_{y M}^{2}}{1-\xi_{x M} \xi_{y M}} \alpha_{y}\left(e_{M M}^{y}-e_{K M}^{y}\right)+\frac{\xi_{y M}\left(1-\xi_{y M}\right)}{1-\xi_{x M} \xi_{y M}} \alpha_{y}\left(e_{K M}^{y}-e_{E M}^{y}\right)\right] \theta_{x e} \tau+\frac{\left(1-\xi_{x M}\right) \xi_{y M} \vartheta_{y}+\xi_{x M}\left(\xi_{y M}-1\right) \vartheta_{x}}{1-\xi_{x M} \xi_{y M}} \frac{\left(1-\xi_{x M}\right)\left(1-\xi_{y M}\right)}{1-\xi_{x M} \xi_{y M}} \theta_{x e} \tau
\end{aligned}
$$

The closed form solution for the percentage change of the real gross domestic product is represented by parameters and the exogenous policy shock. The results show that the sign of the change of real gross domestic product may be positive or negative. This is consistent with the debate on the double-dividend hypothesis of the 
environmental policies (Fullerton and Metcalf, 1998; Goulder, 1995). We can see the scale effect is related to the intermediate input linkage through two different mechanisms. First, the scale effect is influenced by the intermediate input linkage structure, which is represented by the intermediate input coefficient ( $\xi_{x M}$ and $\xi_{y M}$ ). Under the extreme case that two sectors are independent $\left(\xi_{x M}=\xi_{y M}=0\right)$, we obtain $\hat{G}=-\alpha_{x}\left(e_{K E}^{x}-e_{E E}^{x}\right) \theta_{x e} \theta_{x e} \tau-\left(\vartheta_{x} \alpha_{y}-\vartheta_{y} \alpha_{x}\right) \sigma_{u} \theta_{x e} \tau$. We can prove that climate regulations under the carbon intensive sectors would reduce gross economic scale ${ }^{3}$, if we ignore the intermediate input linkage. Second, the scale effect has a close relation with the intermediate substitution elasticity of both regulated and unregulated sectors $\left(e_{M E}^{x}\right.$ and $\left.e_{m M}^{y}\right)$. This reflects the impact of intermediate input linkage change on the environmental effect of climate regulations through the scale effect indirectly.

\subsubsection{Consumption substitution effect}

The final output and final consumption satisfy $O_{x} P_{x}=\xi_{y M} O_{y} P_{y}+C_{x} P_{x}$ and $O_{y} P_{y}=\xi_{x M} O_{x} P_{x}+C_{y} P_{y}$, and we get $\left(\hat{O}_{x}+\hat{P}_{x}\right)=\frac{\vartheta_{x}\left(\hat{C}_{x}+\hat{P}_{x}\right)}{\vartheta_{x}+\xi_{y M} \vartheta_{y}}+\frac{\xi_{y M} \vartheta_{y}\left(\hat{C}_{y}+\hat{P}_{y}\right)}{\vartheta_{x}+\xi_{y M} \vartheta_{y}}$, $\left(\hat{O}_{y}+\hat{P}_{y}\right)=\frac{\xi_{x M} \vartheta_{x}\left(\hat{C}_{x}+\hat{P}_{x}\right)}{\xi_{x M} \vartheta_{x}+\vartheta_{y}}+\frac{\vartheta_{y}\left(\hat{C}_{y}+\hat{P}_{y}\right)}{\xi_{x M} \vartheta_{x}+\vartheta_{y}}$. Inserting them to equation (6), we obtain $N G D P=\vartheta_{x}\left(\hat{C}_{x}+\hat{P}_{x}\right)+\vartheta_{y}\left(\hat{C}_{y}+\hat{P}_{y}\right)$. This can be observed as the mathematical expression of real gross domestic product under the consumption approach. According to the relation between real and nominal gross domestic product $\hat{G}=\hat{N}-\hat{I}$, we obtain

3 When $\xi_{x M}=0$ and $\xi_{y M}=0$, sector $X$ has greater carbon intensity means $\alpha_{y} / \vartheta_{y}>\alpha_{x} / \vartheta_{x}$. According to $e_{E E}^{x}<0$, we obtain $R G D P<0$. 


$$
\hat{G}=\vartheta_{x} \hat{C}_{x}+\vartheta_{y} \hat{C}_{y}
$$

The climate policies shock the final price level faced by consumers, and the change of final prices are $\hat{P}_{x}=\frac{1-\xi_{x M}}{1-\xi_{x M} \xi_{y M}} \theta_{x e} \tau$ and $\hat{P}_{y}=\frac{\left(1-\xi_{x M}\right) \xi_{y M}}{1-\xi_{x M} \xi_{y M}} \theta_{x e} \tau$. When $\xi_{y M}<1$, we obtain $\hat{P}_{x}>\hat{P}_{y}$. This means that the consumer would face a relatively higher price level of products of sector $X$. Then consumers would adjust their consumption structure and improve the share of consumption on products of the sector $Y$. The environmental impact of a consumption structure adjustment due to relative final price change is named the consumption substitution effect (CSE). The mathematical expression is shown below:

$$
\hat{C}_{y}=S E+\underbrace{\frac{\sigma_{u} \vartheta_{x}\left(1-\xi_{x M}\right)\left(1-\xi_{y M}\right) \theta_{x e}}{1-\xi_{x M} \xi_{y M}} \tau}_{C S E}
$$

We can see that the CSE is positive. When $\xi_{x M}=1$ or $\xi_{y M}=1$, all products of sector $Y$ or $X$ are used to satisfy the intermediate demand, and products of two sectors are not substitute. Therefore, the consumption substitution would be zero. $\frac{d C S E}{d \xi_{x M}}<0$ and $\frac{d C S E}{d \xi_{y M}}<0$, this means that the closer the sectoral linkage is, the smaller is the change in relative final price levels, and the scale of the consumption substitution effect would be much smaller.

\subsubsection{Multiplier effect}

According to equation (8), the final output change due to consumption change is influenced by the intermediate input linkage through the multiplier effect $(M E)$. The mathematical expression is shown as below 


$$
\hat{O}_{y}=S E+C S E+\underbrace{\frac{\left(1-\sigma_{u}\right) \vartheta_{x} \xi_{x M}\left(1-\xi_{x M}\right)\left(1-\xi_{y M}\right) \theta_{x e}}{1-\xi_{x M} \xi_{y M}} \tau}_{M E}
$$

The multiplier effect influences the environmental effects of climate policies through impacting the change volume of final products due to final demand change. The sign of $M E$ is determined by the consumption substitution elasticity. The final output and final consumption of the unregulated sector satisfy $\left(1-\xi_{x M} \xi_{y M}\right) O_{y} P_{y}=\xi_{x M} C_{x} P_{x}+C_{y} P_{y}{ }^{4}$. When $\sigma_{u}=1$, the expenditure structure keeps consistent. We can get the final output and consumption share the same percentage change $\left(\hat{O}_{y}=\hat{C}_{y}\right)$, and the multiplier effect has no influence on the change rate of these two variables. $\sigma_{u}>1$ means that the expenditure share has a negative relation with the relative price level, and consumers would decrease the share of gross income spent on the unregulated products; therefore, the sign of $M E$ is negative. $\sigma_{u}<1$ means that consumers would increase the expenditure share of unregulated products, and the sign of $M E$ is positive. In addition, the multiplier effect is closely related to the intermediate input coefficient. When $\xi_{x M}=0$, climate regulations on the upstream firms would face zero multiplier effect of the regional carbon leakage because the products of the downstream industry are all used to satisfy the final consumption.

\subsubsection{Production substitution effect}

Climate policies would shock the production structure, and the environmental effect of the production structure change caused by climate regulations is named the production substitution effect ( $P S E$ ). According to equation (2), we obtain:

\footnotetext{
4 This is obtained from the equations $O_{x} P_{x}=C_{x} P_{x}+\xi_{y M} O_{y} P_{y}$ and $O_{y} P_{y}=C_{y} P_{y}+\xi_{x M} O_{x} P_{x}$.
} 


$$
\hat{E}_{y}=S E+C S E+M E+[\underbrace{\left.\frac{\xi_{y M} \xi_{y M}\left(1-\xi_{x M}\right) \theta_{x e}\left(e_{E M}^{y}-e_{M M}^{y}\right)}{1-\xi_{x M} \xi_{y M}}+\frac{\xi_{y K} \xi_{y M}\left(1-\xi_{x M}\right) \theta_{x e}\left(e_{E M}^{y}-e_{K M}^{y}\right)}{1-\xi_{x M} \xi_{y M}}\right] \tau}_{P S E}
$$

The equation (15) reflects that the proportional change of carbon emissions of the unregulated sector can be explained from the four different effects. The production substitution effect is made up of two parts. The first part is related to the intermediate input structure change and the second part is related to the factor input structure change. Climate regulations would increase the relative price level of regulated products, and the unregulated sector would reduce the intermediate demand for products of the regulated sector and increase the factor demand. At the same time, producers would adjust the factor input structure with the relative price change. The sign of the production substitution effect is determined by the substitution elasticity. We can see that the sign of the production substitution effect is ambiguous. The mathematical expression of carbon leakage appears complex, but we can obtain several simplified forms for special cases. For instance, when substituting the sectoral interdependence $\left(\xi_{x M}=0\right.$ and $\left.\xi_{y M}=0\right)$, the theoretical results are consistent with the Baylis et al.'s model ${ }^{5}$.

\section{The numerical model}

The theoretical model shows the potential impact of the intermediate input linkage on the carbon leakage problem and demonstrates the importance of considering sectoral linkage when discussing the carbon leakage. Given that the electricity is widely used in industrial production as intermediate inputs, and the electricity generation sector is

\footnotetext{
5 When $\xi_{x M}=0$ and $\xi_{y M}=0$, we obtain $\hat{E}_{y}=\sigma_{u} \alpha_{x} \theta_{x e} \tau-\left(\theta_{x e} e_{K E}^{x}-\theta_{x e} e_{E E}^{x}\right) \alpha_{x} \theta_{x e} \tau$. According to the character of Allen substitution elasticity, we obtain $\theta_{i k} e_{K K}^{i}+\theta_{i e} e_{K E}^{i}=0$ and $\theta_{i k} e_{E K}^{i}+\theta_{i e} e_{E E}^{i}=0$. Defining $\sigma_{i}=\theta_{i k} e_{E K}^{i}-\theta_{i k} e_{K K}^{i}=\theta_{i e} e_{K E}^{i}-\theta_{i e} e_{E E}^{i} \quad$ we obtain $\hat{K}_{i}-\hat{E}_{i}=\sigma_{i}\left(\hat{P}_{e i}-\hat{P}_{k}\right)$ and $\hat{E}_{y}=\sigma_{u} \alpha_{x} \theta_{x e} \tau-\sigma_{x} \alpha_{x} \theta_{x e} \tau$, which is just the result of the FKB model (Baylis et al., 2014).
} 
a key target of climate regulations, we take the electricity generation sector as a case to quantitatively evaluate the magnitude of four different leakage effects identified in the theoretical model. To that end, this study builds China's computable general equilibrium model (CGE) and introduces Structural Decomposition Analysis to link both the theoretical and empirical models.

\subsection{CGE model}

The CGE model describes the behaviors of different economic agents (the government, households and enterprises) by a system of equations. To minimize the cost, enterprises use intermediate inputs and factor inputs to produce products, subject to certain technological constraints. Households choose domestic and imported products to maximize utility under budget constraints. As a tax collector, the government determines its expenditures, transfers and savings, according to the tax revenues. The static CGE model constructed by this paper is made up of four blocks: production, consumption and trade, emissions and policy, equilibrium and closure. The database is the social accounting matrix (SAM) of 42 sectors of China in 2007, which is obtained from the Development Research Center of the State Council. The sectoral carbon emissions are calculated based on the fossil fuel demand (NBS, 2008) and carbon emissions factors (IPCC, 2006).

\subsubsection{Production}

The production technology is represented by a five-stage nested constant elasticity of substitution (CES) production function. The nesting structure of production is shown in Figure 1. Being taken out of the intermediate input nest, the energy is incorporated into the value-added nest. The final output is compositions of value-added-energy 
composite and intermediate inputs through a Leontief function. The value-added-energy composite is the composition of capital-energy composite and labor. Labor is divided into agricultural labor, production labor, and professional labor. Energy is divided into electricity and non-electricity. Non-electricity is the composition of coal and non-coal, which is made up of natural gas and refined fossil fuels. The energy substitution elasticities used in this paper are derived from the existing literature (Stern, 2012; Beckman et al., 2011). The capital/energy/labor substitution elasticities are obtained from Lv et al. (2009).

\section{<<insert figure 1 here >>}

\subsubsection{Consumption and trade}

Households earn income from the factor return and government transfer. All the income is spent on commodities, direct taxes, and household savings. To maximize the utility, households' behaviors are described by constant elasticity of substitution function. The consumption demand for certain products is positively related to the real income level and is negatively related to the price level. Under climate regulations, consumers will adjust their consumption structure with the change of income and price levels. The enterprise earns revenue by sold products. The revenue is spent on intermediate goods, transferred to household through factor return, and paid tax to the government. The total domestic demand for manufactured goods is determined by the intermediate input demand of enterprises, final consumption demand of households and the government, and products exported to foreign countries. This demand pool is satisfied by a combination of goods produced by different companies in the domestic market and other regions. We assume that the 
products of different regions compete as imperfect substitutes (the Armington assumption). The elasticity parameters are obtained from the previous literature (Tarr, 2012).

.$<$ insert figure 2 here $>>$

\subsubsection{Emissions and policy}

The sectoral emissions are calculated by multiplying the demand of different fossil by the carbon emissions factors. Under the complete information and perfect competition assumption, the CGE model assumes that the carbon price is equal to the trading price of carbon permits. Qi and Cheng (2015) note that the difference in carbon price of the seven carbon trading pilots decrease gradually, ranging from 24 to 55 Yuan per ton. China's seven carbon emissions trading pilots all cover both direct and indirect emissions from electricity. This study simulates the effect of pricing a carbon at Yuan 30 per ton in the electricity sector. All tax revenues will be returned to the households through payment of transfer. For simplicity, the study assumes that the carbon abatement cost of the electricity generation sector can be passed through to the downstream industries directly ${ }^{6}$.

\footnotetext{
${ }^{6}$ Electricity tariffs have remained controlled by the central government since China split State Power Corporation and separated electricity generation from its transmission and distribution in 2002. While electricity tariffs were raised few times under the coal-electricity price "co-movement" mechanism, they still remain flat and regulated (Zhang, 2014). This not only reduces the effectiveness of addressing the daunting challenges to cut emissions and strengthen industrial upgrading, but also complicates implementing the pilot carbon trading schemes in the power sectors in China. The latter creates a new impetus for power pricing reforms to allow the pass-through of carbon costs in the electricity sector as a result of implementing carbon trading (Zhang, 2015a,b). The encouraging sign is that the central government recently released several documents to further deepen and speed up the reform of power pricing reform (The Central Committee of Communist Party of China and The State Council, 2015; The State Council, 2016).
} 


\subsubsection{Equilibrium and closure}

CGE model incorporates commodity market, factor market, and exchange market of domestic and foreign products. The equilibrium module presents the clearance of each market. For instance, commodity market clearance implies that the value of gross output equals the sum of intermediate input and final demands. The closure module describes the balance of saving-investment, government budget, and international payments. This paper adopts the neoclassical closure principle. First, total investment in the economy is adjusted to the gross savings (household savings, corporate savings, government savings, public sector surplus earnings and foreign savings) to balance the savings-investment closure. Secondly, the tax rate, transfer payments and government consumption are fixed, while government saving is endogenous to balance the government budget closure. Thirdly, the exchange rate is endogenously determined to balance the international payments.

\subsection{Structural decomposition analysis}

Using the numerical model presented above, we could simulate the economic and environmental effects of climate regulations on the electricity generation sector. However, CGE model only reports the single net aggregated simulation result without showing the fact that different effect may be offset against each other (Baylis et al., 2014). This study introduces the Structural Decomposition Analysis to numerically evaluate the four different leakage effects presented in the theoretical model. We suppose that $G$ represents the real gross domestic product, $S$ represents the sectoral share of final demand, $B$ represents the Leontif matrix $(1-A)^{-1}, F$ represents the sectoral carbon matrix, which is related to the energy consumption structure and carbon emission coefficient of the fossil energy. The sectoral direct 
emissions satisfy

$$
E=F B S G
$$

According to the structural decomposition analysis, the change of sector emissions is presented below:

$$
\begin{aligned}
E^{\prime}-E^{0} & =F^{\prime} B^{\prime} S^{\prime} G^{\prime}-F^{0} B^{0} S^{0} G^{0} \\
& =\underbrace{F^{0} I S^{0}\left(G^{\prime}-G^{0}\right)}_{\text {SE }} \underbrace{+F^{0} I\left(S^{\prime}-S^{0}\right)^{\prime} G^{\prime}}_{\text {CSE }} \underbrace{+F^{0}\left(B^{0}-I\right)\left(S^{\prime} G^{\prime}-S^{0} G^{0}\right)}_{\text {PSE }} \\
& \underbrace{+\left(F^{\prime} B^{\prime}-F^{0} B^{0}\right) S^{\prime} G^{\prime}}_{\text {PE }}
\end{aligned}
$$

The first part reflects the environmental effect of climate regulations due to the gross economic scale change, which reflects the scale effect. The second part reflects the change of carbon emissions due to the consumption structure change, which is related to the consumption substitution effect. The intermediate input linkage $\left(B^{0}-I\right)$ has an amplification effect on the scale and consumption substitution effects of carbon leakage, which represents the multiplier effect. Being consistent with the theoretical model, the fourth part reflects the production substitution effect, which is related to both the change of intermediate input structure and energy consumption structure.

\section{Numerical results}

This section presents numerical simulations of the economic and environmental effects of carbon regulation. We aggregate the 42 sector in the CGE model into agricultural, industrial, and service sectors.

\section{$<<$ insert table 1 here $>>$}

Table 1 shows the economic effects of the policy simulation at both macro and sectoral levels. It should be pointed out that the CGE model in this study is a static model, which focuses on the short-term effects of climate regulations. Climate regulations on the electricity generation sector have a negative impact on the economy 
scale, represented by real GDP. The results show that the change rate of real GDP is $-0.32 \%$. This means the carbon pricing would put a downward pressure on China's economic growth in the short term. At sectoral level, climate regulations have a much more severe impact on the industrial sector, especially the electricity generation sector. The electricity production decreases by $5.45 \%$. At the same time, the gross emissions and carbon intensity decrease by $4.12 \%$ and $3.81 \%$, respectively. This means that the carbon pricing would help to achieve China's target of $40-45 \%$ carbon intensity reduction by 2020, compared with 2005 level. In addition, climate regulations increase the overall price level. The consumer price index (CPI) increases by $0.51 \%$. The electricity price level would increase by $3.55 \%$, which would further raise the production cost of other sectors. We further present the environmental effects of climate regulation and decompose the sectoral emissions change into different terms. The aggregated results are presented in Table 2 and the decomposition of sectoral emissions change is presented in Appendix B.

\section{$<$ insert table 2 here $>>$}

As shown in Table 2, we decompose the change of sectoral emissions into four components: the scale effect, the consumption substitution effect, the multiplier effect, and the production substitution effect. The first four columns present the volume and percentage changes in sectoral emissions due to four different effects, and the last column shows the overall change. The results suggest that the climate regulation reduces the emissions of unregulated and regulated sectors by 38.79 and 171.51 million tons. Defined as the share of the change in unregulated-sector emissions to the reduction in regulated-sector emissions, the sectoral carbon leakage rate is $22.62 \%$.

The numerical simulations show that imposing a carbon price of Yuan 30 per ton on Chin's electricity generation sector would decrease GDP by $0.32 \%$. This explains 
the negative sign of the scale effect on the emissions of unregulated sectors. For example, the scale effect contributes to a decrease in carbon emissions of the agricultural sector by $0.10 \%$ or 129.38 thousand tons. Carbon pricing regulation would increase the electricity price level and the price of other products that use electricity as intermediate input. The industrial sector is more sensitive to the electricity price, which would have a relatively higher price level. Consumers adjust the consumption structure, and the consumption substitution effect leads to increases in carbon emissions of the agricultural and service industries.

Table 2 shows that the multiplier effect contributes to negative carbon leakage. The climate regulation shrinks the final demand, and the final output and emissions correspond to a larger decrease because the amplification effect of the sectoral linkage. Therefore, the multiplier effect has a negative sign. At the same time, climate regulations shock the intermediate input structure. For instance, the climate regulation promotes firms to use more clean intermediate and factor inputs, so the production substitution effect also corresponds to negative carbon leakage. Both the multiplier effect and the production substitution effect are closely related to the sectoral linkage.

\section{Conclusions}

Climate regulations tend to cover a limited number of energy-intensive sectors and thus lead to the carbon leakage across sectors. Considering that the regulated products, such as electricity, are widely used in industrial production as intermediate inputs, we attempt to disentangle the influence mechanism of intermediate input linkage on the carbon leakage problem.

This present study develops a Harberger-type model considering the sectoral intermediate input linkage structure and provides the closed form solutions for four 
leakage effects. We find that intermediate input linkage has important implications for assessing the carbon leakage. The sectoral linkage directly impacts the carbon leakage problem through the multiplier effect. At the same time, producers would adjust the intermediate input structure due to climate policies, which is related to the production substitution effect. In addition, the sectoral linkage has an impact on the magnitude of the scale effect and the consumption substitution effects. This present study builds China's computable general equilibrium model, proposes a method to link the theoretical and numerical models by adopting Structural Decomposition Analysis and examines the effects of China's climate regulations on the electricity generation sector The numerical results show that climate regulations on the electricity generation sector would result in a significant leakage, which is mainly determined by the production substitution effect, followed by the multiplier effect. Both two effects are closely related to the sectoral linkage. This highlights the importance of considering intermediate input linkage when discussing the carbon leakage problem of climate policies.

There are several potential extensions. First, the theoretical model constructed by this study can also represent two countries linked through intermediate goods trade, which could be adopted to analyze the regional carbon leakage of unilateral climate policies. Second, this study only discusses four different carbon leakage effects. Future studies could discuss the other leakage channels omitted by this study. Third, the empirical study adopts parameters from the literature rather than being estimated econometrically. The theoretical model shows that carbon leakage is sensitive to substitution elasticities; therefore, future studies should address this issue. Finally, this study discusses the environmental effect of China's climate regulations on the electricity generation sector, and the analytical framework of this study can be 
adopted to discuss climate policies of the other regions.

\section{Acknowledgements}

The authors gratefully acknowledge the financial support from the National Science Foundation of China (Grant NOs. 71603179, 71173169, 71203064 and 71373055), the National Social Sciences Fund (Grant NO. 15AGL024), and Tianjin Science and Technology Development Strategy Key Project (Grant NO. 14ZLZLZF00008).

\section{References}

Antimiani, A., Costantini, V., Martini, C., Salvatici, L., Tommasino, M.C., 2013. Assessing alternative solutions to carbon leakage. Energy Economics 36, 299-311.

Babiker, M.H., 2001. Subglobal climate-change actions and carbon leakage: the implication of international capital flows. Energy Economics 23, 121-139.

Barker, T., Junankar, S., Pollitt, H., Summerton, P., 2007. Carbon leakage from unilateral environmental tax reforms in Europe, 1995-2005. Energy Policy 35, 6281-6292.

Baylis, K., Fullerton, D., Karney, D.H., 2013. Leakage, welfare, and cost-effectiveness of carbon policy. American Economic Review 103, 332-337.

Baylis, K., Fullerton, D., Karney, D.H., 2014. Negative leakage. Journal of the Association of Environmental and Resource Economists 1, 51-73.

Beckman, J., Hertel, T., Tyner, W., 2011. Validating energy-oriented CGE models. Energy Economics 33, 799-806.

Bernstein, P.M., Montgomery, W.D., Rutherford, T.F., 1999. Global impacts of the Kyoto agreement: results from the MS-MRT model. Resource and Energy Economics 21, 375-413.

Böhringer, C., Rivers, N., Yonezawa, H., 2016. Vertical fiscal externalities and the environment. Journal of Environmental Economics and Management 77, 51-74.

Böhringer, C, Müller, A, Schneider, J., 2014. Carbon tariffs revisited, Oldenburg Discussion Papers in Economics, No. V-364-14.

Bruvoll A, Faehn T., 2006. Transboundary effects of environmental policy: markets and emission leakages. Ecological Economics 59, 499-510.

Bushnell, J.B., Mansur, E.T., 2011. Vertical targeting and leakage in carbon policy. American Economic Review 101, 1-8.

Carbone J C., 2013. Linking numerical and analytical models of carbon leakage. American Economic Review 103, 326-331.

Chumacero, R.A., Schmidt-Hebbel, K., 2004. General equilibrium models: an overview. Working Papers Central Bank of Chile.

Di Maria, C., Van der Werf, E., 2008. Carbon leakage revisited: unilateral climate policy with directed technical change. Environmental and Resource Economics 39, 55-74. 
Dröge, S., Asselt, H.v., Schumacher, K., Brewer, T., Mohr, L., 2009. Tackling leakage in a world of unequal carbon prices. Climate Strategies 1, 2-16.

Eichner, T., Pethig, R., 2015. Unilateral consumption-based carbon taxes and negative leakage. Resource and Energy Economics 40, 127-142.

Elliott, J., Fullerton, D., 2014. Can a unilateral carbon tax reduce emissions elsewhere? Resource and Energy Economics 36, 6-21.

Fullerton, D., Karney, D.H., Baylis, K., 2012. Negative leakage. Working paper. Source: http://gatton.uky.edu/Units/Downloads/Fullerton.pdf

Fullerton, D., Heutel, G., 2007. The general equilibrium incidence of environmental taxes. Journal of Public Economics 91, 571-591.

Fullerton, D, Metcalf G E., 1998. Environmental taxes and the double-dividend hypothesis: did you really expect something for nothing? Chicago-Kent Law Review 73, 221-256.

Fullerton D, Monti H., 2013. Can pollution tax rebates protect low-wage earners? Journal of Environmental Economics and Management 66, 539-553.

Gerlagh, R, Kuik O., 2014. Spill or leak? Carbon leakage with international technology spillovers: a CGE analysis. Energy Economics 45, 381-388.

Golombek, R., Hoel, M., 2004. Unilateral emission reductions and cross-country Technology Spillovers. The B.E. Journal of Economic Analysis \& Policy 3.

Goulder, L. 1995. Environmental taxation and the double dividend: a reader's guide. International Tax and Public Finance 2, 157-183.

Harberger, A.C., 1962. The incidence of the corporation income tax. Journal of Political Economy 70, 215-240.

IPCC, 2006. The 2006 IPCC Guidelines for National Greenhouse Gas Inventories (2006 Guidelines). http://www.ipcc-nggip.iges.or.jp/public/2006 gl/index.html.

Karney, D.H., 2016. General equilibrium models with Morishima elasticities of substitution in production. Economic Modelling 53, 266-277.

Karp, L., 2013. The income and production effects of leakage. http://are.berkeley.edu/ karp/leakage_aug_2013.pdf

Kortum, S., 2011. Comment on "Analytical general equilibrium effects of energy policy on output and factor prices". The B.E. Journal of Economic Analysis \& Policy 10.

Kuik, O., Gerlagh, R., 2003. Trade liberalization and carbon leakage. The Energy Journal 24, 97-120.

Lanzi E, Wing I S., 2013. Capital malleability, emission leakage and the cost of partial climate policies: general equilibrium analysis of the European Union emission trading system. Environmental and Resource Economics 55(2), 257-289.

Lv, Z.D., Guo, J.E., Xi, Y.M., 2009. Econometric estimate and selection on China energy CES production function. China population resources and environment 19, 156-160.

Mathiesen, L., Mæstad, O., 2004. Climate policy and the steel industry: achieving global emission reductions by an incomplete climate agreement. Energy Journal 25, 91-114.

Michielsen, T.O., 2014. Brown backstops versus the green paradox. Journal of Environmental Economics and Management 68, 87-110.

Meunier, G., Ponssard, J.P., Quirion, P., 2014. Carbon leakage and capacity-based allocations: Is the EU right? Journal of Environmental Economics and Management 68, 262-279.

National Bureau of Statistics of China (NBS), 2008. China energy statistical year book 2008. 
China Statistics Press, Beijing.

Qi, S., Cheng, S., 2015. Comparative studies in China's pilot emissions trading schemes. Annual Review of Low-Carbon Development in China 2015. Sources: http://www.brookings.edu/.

Rausch, S, Giacomo S., 2016. Household heterogeneity, aggregation, and the distributional impacts of environmental taxes. CER-ETH, Center of Economic Research at ETH Zurich, Working Paper.

Sen, P., 2015. Unilateral emission cuts and carbon leakages in a dynamic north-south trade model. Environmental and Resource Economics 60, 1-22.

Sijm, J P M, Kuik O J, Patel M, et al., 2004. Spillovers of climate policy-an assessment of the incidence of carbon leakage and induced technological change due to $\mathrm{CO} 2$ abatement measures. 500036002 (ECN-C--05-014). Netherlands Research Programme on Climate Change.

Stern, D I., 2012. Interfuel substitution: a meta-analysis. Journal of Economic Surveys 26, 307-331.

Tarr, D., 2012. Putting services and foreign direct investment with endogenous productivity effects in computable general equilibrium models. World Bank Policy Research Working Paper.

The Central Committee of Communist Party of China and The State Council, 2015. Several opinions on further deepening the reform of the electric power system. March 15. http://www.ne21.com/news/show-64828.html.

The State Council, 2016. A circular on work options to lower the cost of firms in the real economy. August 8, http://yxj.ndrc.gov.cn/zttp/jdjjcbgz/zccs/201608/t20160829 816307.html.

UNFCCC (United Nations Framework Convention on Climate Change), 2015. Adoption of the Paris Agreement. FCCC/CP/2015/L.9/Rev.1, http://unfccc.int/resource/docs/2015/cop21/eng/109r01.pdf.

World Bank, 2015. Carbon leakage: theory, evidence, and policy design. Sources: http://documents.worldbank.org/curated/en/2015/10/25189663/carbon-leakage-theory-evidence-p olicy-design.

World Bank, 2015. Carbon leakage: theory, evidence, and policy design. Sources: http://documents.worldbank.org/curated/en/2015/10/25189663/carbon-leakage-theory-evidence-p olicy-design.

Xu, Y., Dietzenbacher, E., 2014. A structural decomposition analysis of the emissions embodied in trade. Ecological Economics 101, 10-20.

Zhang, Z X., 2012. Competitiveness and leakage concerns and border carbon adjustments. International Review of Environmental and Resource Economics 6, 225-287.

Zhang, Z X., 2014. Energy prices, subsidies and resource tax reform in China. Asia and the Pacific Policy Studies 1(3), 439-454.

Zhang, Z X., 2015a. Crossing the river by feeling the stones: the case of carbon trading in China. Environmental Economics and Policy Studies 17(2), 263-297.

Zhang, Z X., 2015b. Carbon emissions trading in China: the evolution from pilots to a nationwide scheme. Climate Policy 15, S104-S126. 


\section{Appendix A. Parameters, variables and equations of the theoretical model}

Table A 1. Parameters, variables and equations of the theoretical model

(a) Parameters of the theoretical model

\begin{tabular}{cl}
\hline Parameters & Explanations \\
\hline$i, j$ & Sector \\
$m, n$ & Factor inputs \\
$k$ & Capital \\
$e$ & Allen elasticity \\
$\xi$ & Intermediate and factor input share \\
$\theta$ & Clean and dirty factor input share \\
$\sigma$ & Substitution elasticity \\
$\alpha$ & Capital distribution \\
$\beta$ & Carbon distribution \\
$\vartheta$ & Total income distribution \\
$\tau$ & Climate policy shock \\
\hline
\end{tabular}

(b) Variables of the theoretical model

\begin{tabular}{cl}
\hline Variables & Explanations \\
\hline$\hat{O}_{x}$ & Proportional change of the output of sector $X$ \\
$\hat{O}_{y}$ & Proportional change of the output of sector $Y$ \\
$\hat{C}_{x}$ & Proportional change of the consumption demand of sector $X$ \\
$\hat{C}_{y}$ & Proportional change of the consumption demand of sector $Y$ \\
$\hat{M}_{x}$ & Proportional change of the intermediate input of sector $X$ \\
$\hat{M}_{y}$ & Proportional change of the intermediate input of sector $Y$ \\
$\hat{E}_{x}$ & Proportional change of the carbon emissions of sector $X$ \\
$\hat{E}_{y}$ & Proportional change of the carbon emissions of sector $Y$ \\
$\hat{K}_{x}$ & Proportional change of the capital input of sector $X$ \\
$\hat{K}_{y}$ & Proportional change of the capital input of sector $Y$ \\
$\hat{P}_{e x}$ & Proportional change of the carbon price of sector $X$ \\
$\hat{P}_{e y}$ & Proportional change of the carbon price of sector $Y$ \\
$\hat{P}_{x}$ & Proportional change of the final output price of sector $X$ \\
$\hat{P}_{y}$ & Proportional change of the final output price of sector $Y$ \\
$\hat{P}_{k}$ & Proportional change of the capital return \\
$\hat{I}$ & Proportional change of the total price level \\
$\hat{N}$ & Proportional change of the nominal GDP \\
\hline & Proportional change of the real GDP \\
\hline
\end{tabular}


(c) Equations of the theoretical model

\begin{tabular}{|c|c|}
\hline Modules & Equations \\
\hline $\begin{array}{l}\text { Production } \\
\text { module }\end{array}$ & 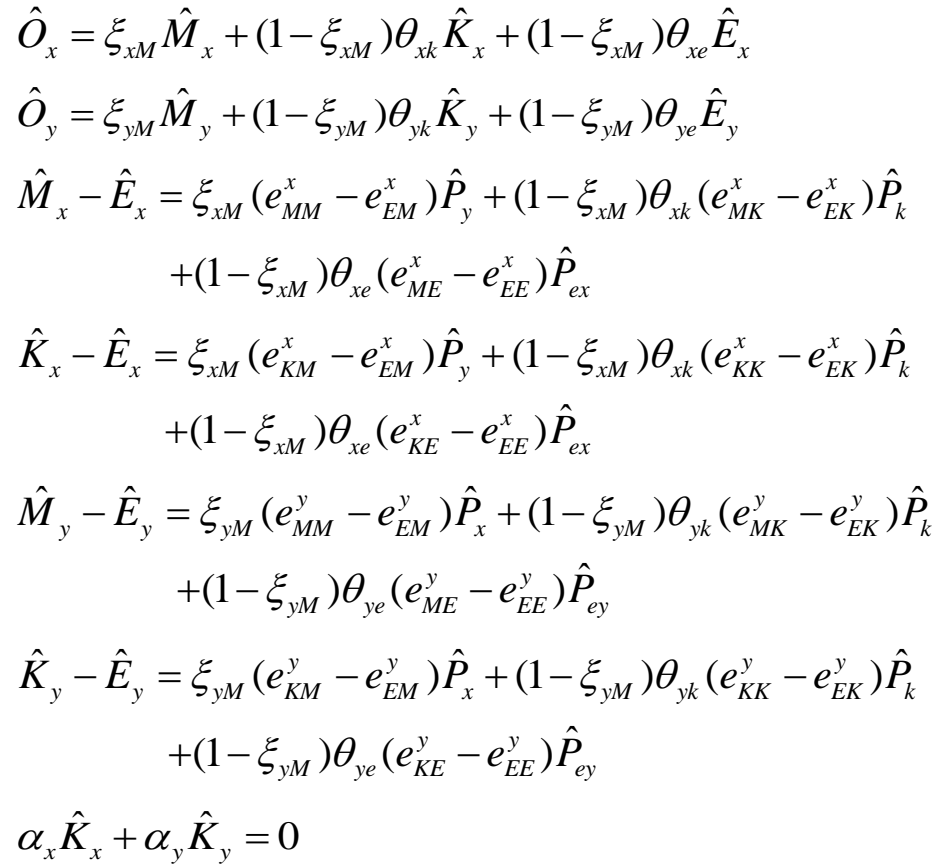 \\
\hline Price module & $\begin{array}{l}\hat{P}_{x}=\xi_{x M} \hat{P}_{y}+\left(1-\xi_{x M}\right)\left(\theta_{x k} \hat{P}_{k}+\theta_{x e} \hat{P}_{e x}\right) \\
\hat{P}_{y}=\xi_{y M} \hat{P}_{x}+\left(1-\xi_{y M}\right)\left(\theta_{y k} \hat{P}_{k}+\theta_{y e} \hat{P}_{e y}\right) \\
\hat{I}=\vartheta_{x} \hat{P}_{x}+\vartheta_{y} \hat{P}_{y} \\
\hat{N}=\frac{\vartheta_{x}+\xi_{y M} \vartheta_{y}}{1-\xi_{x M} \xi_{y M}}\left(1-\xi_{x M}\right)\left(\hat{O}_{x}+\hat{P}_{x}\right)+\frac{\xi_{x M} \vartheta_{x}+\vartheta_{y}}{1-\xi_{x M} \xi_{y M}}\left(1-\xi_{y M}\right)\left(\hat{O}_{y}+\hat{P}_{y}\right) \\
\hat{G}=\hat{N}-\hat{I} \\
\hat{P}_{k}=0\end{array}$ \\
\hline $\begin{array}{l}\text { Consumption } \\
\text { module }\end{array}$ & $\begin{array}{l}\hat{C}_{x}-\hat{C}_{y}=\sigma_{u}\left(\hat{P}_{y}-\hat{P}_{x}\right) \\
\hat{O}_{x}=\hat{C}_{x}+\frac{\left(\sigma_{u}-1\right) \xi_{y M} \vartheta_{y}}{\vartheta_{x}+\xi_{y M} \vartheta_{y}}\left(\hat{P}_{x}-\hat{P}_{y}\right) \\
\hat{O}_{y}=\hat{C}_{y}+\frac{\left(\sigma_{u}-1\right) \xi_{x M} \vartheta_{x}}{\xi_{x M} \vartheta_{x}+\vartheta_{y}}\left(\hat{P}_{y}-\hat{P}_{x}\right)\end{array}$ \\
\hline Policy module & $\begin{array}{l}\hat{P}_{e x}=\tau \\
\hat{P}_{e y}=0\end{array}$ \\
\hline
\end{tabular}




\section{Appendix B. Decomposition analysis of sectoral emissions change}

\begin{tabular}{|c|c|c|c|c|c|c|}
\hline & Sectors & SE & CSE & $\mathrm{ME}$ & PSE & Sum \\
\hline 01 & Agricultural & $-0.10 \%$ & $0.13 \%$ & $-0.13 \%$ & $-2.27 \%$ & $-2.36 \%$ \\
\hline 02 & Coal Ming & $0.00 \%$ & $0.00 \%$ & $-1.06 \%$ & $-3.44 \%$ & $-4.51 \%$ \\
\hline 03 & Crude Oil Mining & $0.19 \%$ & $0.01 \%$ & $-1.05 \%$ & $-3.36 \%$ & $-4.21 \%$ \\
\hline 04 & Metal Ore Mining & $0.20 \%$ & $-1.58 \%$ & $-1.24 \%$ & $-1.44 \%$ & $-4.06 \%$ \\
\hline 05 & Nonmetal Ore Mining & $0.01 \%$ & $-0.20 \%$ & $-0.29 \%$ & $-1.43 \%$ & $-1.91 \%$ \\
\hline 06 & Food & $-0.15 \%$ & $0.14 \%$ & $-0.10 \%$ & $-2.02 \%$ & $-2.14 \%$ \\
\hline 07 & Textile & $-0.09 \%$ & $0.03 \%$ & $-0.19 \%$ & $-2.08 \%$ & $-2.33 \%$ \\
\hline 08 & Apparel & $-0.21 \%$ & $0.09 \%$ & $-0.10 \%$ & $-1.41 \%$ & $-1.63 \%$ \\
\hline 09 & Wood Processing & $-0.11 \%$ & $0.07 \%$ & $-0.11 \%$ & $-2.05 \%$ & $-2.20 \%$ \\
\hline 10 & Paper & $-0.04 \%$ & $-0.06 \%$ & $-0.29 \%$ & $-2.09 \%$ & $-2.47 \%$ \\
\hline 11 & Oil Processing & $0.01 \%$ & $-0.04 \%$ & $-0.57 \%$ & $-1.28 \%$ & $-1.88 \%$ \\
\hline 12 & Chemical & $0.00 \%$ & $-0.34 \%$ & $-0.57 \%$ & $-0.87 \%$ & $-1.79 \%$ \\
\hline 13 & Nonmetallic Mineral Products & $-0.01 \%$ & $-0.06 \%$ & $0.02 \%$ & $-1.06 \%$ & $-1.11 \%$ \\
\hline 14 & Metal Smelting & $0.00 \%$ & $-0.21 \%$ & $-0.43 \%$ & $-0.97 \%$ & $-1.61 \%$ \\
\hline 15 & Metal Products & $-0.07 \%$ & $-0.05 \%$ & $-0.32 \%$ & $-1.91 \%$ & $-2.35 \%$ \\
\hline 16 & Machinery & $-0.12 \%$ & $-0.09 \%$ & $-0.32 \%$ & $-1.87 \%$ & $-2.40 \%$ \\
\hline 17 & Transport Equipment & $-0.14 \%$ & $0.02 \%$ & $-0.19 \%$ & $-2.10 \%$ & $-2.41 \%$ \\
\hline 18 & Electronic Machine & $-0.12 \%$ & $-0.10 \%$ & $-0.33 \%$ & $-2.18 \%$ & $-2.73 \%$ \\
\hline 19 & Telecommunications Equipment & $-0.09 \%$ & $-0.24 \%$ & $-0.53 \%$ & $-2.23 \%$ & $-3.10 \%$ \\
\hline 20 & Instrument & $-0.04 \%$ & $-0.21 \%$ & $-0.59 \%$ & $-2.54 \%$ & $-3.38 \%$ \\
\hline 21 & Other Manufacturing & $-0.19 \%$ & $0.02 \%$ & $-0.17 \%$ & $-1.84 \%$ & $-2.18 \%$ \\
\hline 22 & Waste & $0.09 \%$ & $0.31 \%$ & $-0.66 \%$ & $-2.34 \%$ & $-2.60 \%$ \\
\hline 23 & Electricity Production & $-0.01 \%$ & $-0.93 \%$ & $-1.06 \%$ & $-3.78 \%$ & $-5.78 \%$ \\
\hline 24 & Gas & $-0.11 \%$ & $-0.01 \%$ & $-0.44 \%$ & $-1.27 \%$ & $-1.84 \%$ \\
\hline 25 & Water & $-0.08 \%$ & $-0.83 \%$ & $-0.42 \%$ & $-2.39 \%$ & $-3.72 \%$ \\
\hline 26 & Construction & $-0.31 \%$ & $0.58 \%$ & $0.00 \%$ & $-1.29 \%$ & $-1.03 \%$ \\
\hline 27 & Transport & $-0.07 \%$ & $0.08 \%$ & $-0.22 \%$ & $-0.58 \%$ & $-0.80 \%$ \\
\hline 28 & Post & $-0.04 \%$ & $0.01 \%$ & $-0.22 \%$ & $-1.37 \%$ & $-1.61 \%$ \\
\hline 29 & Information Transmission & $-0.15 \%$ & $0.25 \%$ & $-0.15 \%$ & $-2.72 \%$ & $-2.76 \%$ \\
\hline 30 & Commerce & $-0.16 \%$ & $0.27 \%$ & $-0.20 \%$ & $-2.33 \%$ & $-2.41 \%$ \\
\hline 31 & Restaurant & $-0.14 \%$ & $0.11 \%$ & $-0.14 \%$ & $-2.01 \%$ & $-2.18 \%$ \\
\hline 32 & Finance & $-0.08 \%$ & $0.24 \%$ & $-0.33 \%$ & $-2.15 \%$ & $-2.33 \%$ \\
\hline 33 & Real Estate & $-0.24 \%$ & $0.82 \%$ & $-0.05 \%$ & $-1.27 \%$ & $-0.74 \%$ \\
\hline 34 & Lease Business & $-0.07 \%$ & $-0.05 \%$ & $-0.22 \%$ & $-1.06 \%$ & $-1.40 \%$ \\
\hline 35 & Travel & $-0.01 \%$ & $-0.17 \%$ & $-0.50 \%$ & $-2.24 \%$ & $-2.91 \%$ \\
\hline 36 & Science & $-0.08 \%$ & $0.11 \%$ & $-0.32 \%$ & $-1.31 \%$ & $-1.60 \%$ \\
\hline 37 & Technical Services & $-0.22 \%$ & $0.22 \%$ & $-0.16 \%$ & $-1.44 \%$ & $-1.60 \%$ \\
\hline 38 & Other Social Services & $-0.16 \%$ & $0.20 \%$ & $-0.17 \%$ & $-1.38 \%$ & $-1.52 \%$ \\
\hline 39 & Education & $-0.29 \%$ & $0.25 \%$ & $-0.02 \%$ & $-2.30 \%$ & $-2.36 \%$ \\
\hline 40 & Health, Security, Welfare & $-0.29 \%$ & $0.05 \%$ & $-0.05 \%$ & $-2.11 \%$ & $-2.40 \%$ \\
\hline 41 & Culture, Sports, Entertainment & $-0.15 \%$ & $0.13 \%$ & $-0.15 \%$ & $-1.82 \%$ & $-1.99 \%$ \\
\hline
\end{tabular}




\begin{tabular}{llccccc}
\hline & Sectors & SE & CSE & ME & PSE & Sum \\
\hline 42 & Public Administrate & $-0.32 \%$ & $0.32 \%$ & $0.00 \%$ & $-1.62 \%$ & $-1.62 \%$ \\
\hline
\end{tabular}

Notes: The scale effect may contribute to an increase in sectoral emissions because the sectoral share of GDP can be negative. For instance, the mining sector has big trade deficit, which results in negative sectoral share of GDP for the mining sector. The consumption effect may contribute to negative carbon leakage because these sectors are closely related to the electricity sector either directly or indirectly. 


\section{Figures}

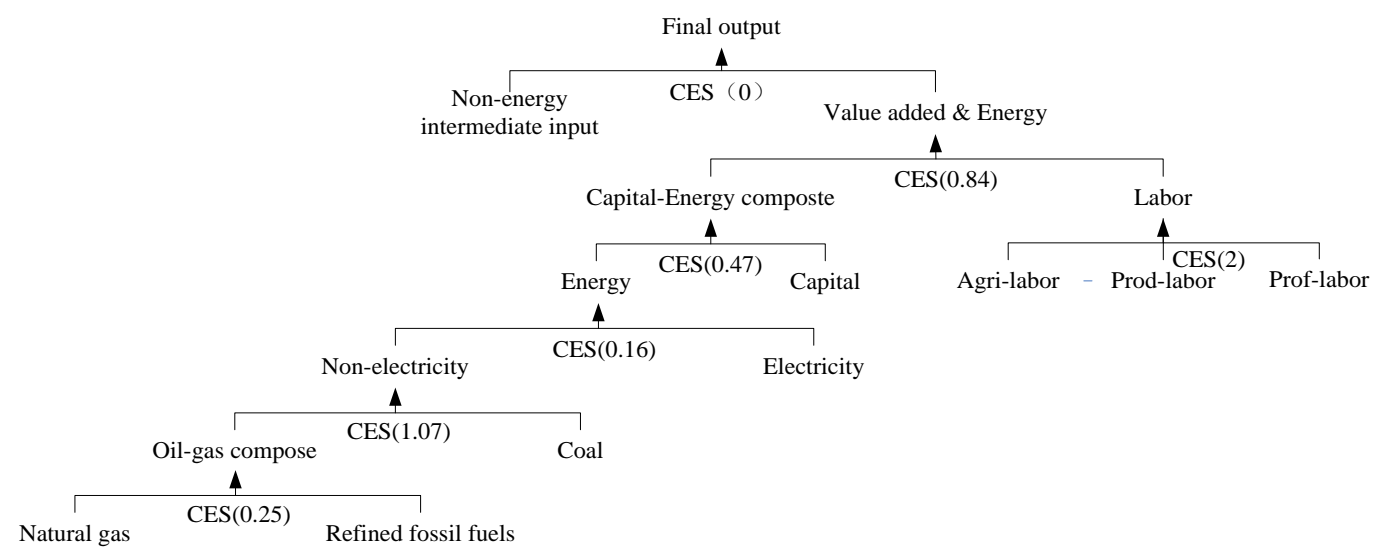

Figure 1. Production structure of the CGE model

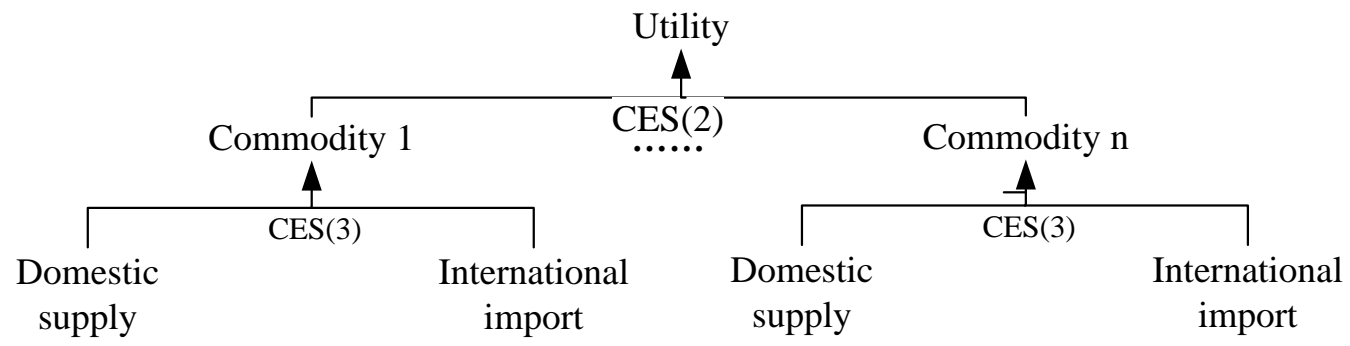

Figure 2. Consumption structure of the CGE model 


\section{Tables}

Table 1. Aggregated effects of climate regulations

\begin{tabular}{|c|c|c|c|c|c|}
\hline & Change rate & & & Output change rate & Price change rate \\
\hline Real GDP & $-0.32 \%$ & \multicolumn{2}{|c|}{ Agriculture } & $-0.15 \%$ & $0.23 \%$ \\
\hline Gross emissions & $-4.12 \%$ & \multirow{2}{*}{ Industry } & Electricity & $-5.45 \%$ & $3.55 \%$ \\
\hline Carbon intensity & $-3.81 \%$ & & Other industries & $-0.71 \%$ & $0.83 \%$ \\
\hline CPI & $0.51 \%$ & Service & & $-0.25 \%$ & $0.23 \%$ \\
\hline
\end{tabular}

Table 2. Decomposition analysis of environmental effects of climate regulations (thousand tons)

\begin{tabular}{|c|c|c|c|c|c|c|}
\hline & & $\mathrm{SE}$ & CSE & $\mathrm{ME}$ & PSE & Sum \\
\hline \multirow{2}{*}{\multicolumn{2}{|c|}{ Agriculture }} & -129.38 & 173.27 & -171.76 & -3050.33 & -3178.20 \\
\hline & & $(-0.10 \%)$ & $(0.13 \%)$ & $(-0.13 \%)$ & $(-2.27 \%)$ & $(-2.36 \%)$ \\
\hline \multirow{4}{*}{ Industry } & & -355.78 & -27602.37 & -31478.14 & -112070.22 & -171506.51 \\
\hline & Electricity & $(-0.01 \%)$ & $(-0.93 \%)$ & $(-1.06 \%)$ & $(-3.78 \%)$ & $(-5.78 \%)$ \\
\hline & & -575.80 & -1669.89 & -5809.16 & -23214.79 & -31269.64 \\
\hline & Other industries & $(-0.04 \%)$ & $(-0.10 \%)$ & $(-0.36 \%)$ & $(-1.43 \%)$ & $(-1.93 \%)$ \\
\hline \multirow{2}{*}{ Services } & & -400.27 & 393.61 & -757.14 & -3569.84 & -4333.66 \\
\hline & & $(-0.11 \%)$ & $(0.10 \%)$ & $(-0.20 \%)$ & $(-0.94 \%)$ & $(-1.14 \%)$ \\
\hline
\end{tabular}

Notes: The number in parentheses represents the change rate of sectoral emissions (\%). SE: scale effect; CSE: consumption substitution effect; ME: multiplier effect; PSE: production substitution effect. 